\title{
Erosive wear properties of ZA-27 alloy-based nanocomposites: Influence of type, amount, and size of nanoparticle reinforcements
}

\author{
Aleksandar VENCL ${ }^{1, *}$, Ilija BOBIĆ ${ }^{2}$, Biljana BOBIĆ ${ }^{3}$, Kristina JAKIMOVSKA ${ }^{4}$, Petr SVOBODA ${ }^{5}$, Mara KANDEVA \\ ${ }^{1}$ Faculty of Mechanical Engineering, University of Belgrade, Kraljice Marije 16, Belgrade 11120, Serbia \\ ${ }^{2}$ Institute of Nuclear Sciences “Vinca”, University of Belgrade, Mike Petrovića Alasa 12-14, Belgrade 11001, Serbia \\ ${ }^{3}$ Institute of Chemistry, Technology and Metallurgy, University of Belgrade, Njegoševa 12, Belgrade 11000, Serbia \\ ${ }^{4}$ Faculty of Mechanical Engineering in Skopje, Ss. Cyril and Methodius University, Karposh II bb, Skopje 1000, Macedonia \\ ${ }^{5}$ Faculty of Mechanical Engineering, Brno University of Technology, Technická 2896/2, Brno 61669, Czech Republic \\ ${ }^{6}$ Faculty of Industrial Technology, Technical University of Sofia, 8 Kliment Ohridski Blvd, Sofia 1000, Bulgaria \\ Received: 08 March 2018 / Revised: 12 April 2018 / Accepted: 09 May 2018 \\ (C) The author(s) 2018. This article is published with open access at Springerlink.com
}

\begin{abstract}
Metal matrix nanocomposites (MMnCs) comprise a metal matrix filled with nanosized reinforcements with physical and mechanical properties that are very different from those of the matrix. In ZA-27 alloy-based nanocomposites, the metal matrix provides ductility and toughness, while usually used ceramic reinforcements give high strength and hardness. Tested ZA-27 alloy-based nanocomposites, reinforced with different types (SiC and $\left.\mathrm{Al}_{2} \mathrm{O}_{3}\right)$, amounts $(0.2 \mathrm{wt} . \%, 0.3 \mathrm{wt} . \%$, and $0.5 \mathrm{wt} . \%)$ and sizes $(25 \mathrm{~nm}, 50 \mathrm{~nm}$, and $100 \mathrm{~nm}$ ) of nanoparticles were produced through the compocasting process with mechanical alloying pre-processing (ball milling). It was previously shown that the presence of nanoparticles in ZA-27 alloy-based nanocomposites led to the formation of a finer structure in the nanocomposites matrix and an improvement in the basic mechanical properties (hardness and compressive yield strength) through the enhanced dislocation density strengthening mechanism. Solid particle erosive wear testing demonstrated that these improvements were followed with an increase in the erosive wear resistance of tested nanocomposites, as well. Additionally, by analyzing the influences of type, amount, and size of nanoparticles on the erosive wear resistance of nanocomposites, it was demonstrated that there is an optimal amount of nanoparticles, which in our case is $0.3 \mathrm{wt} \%$, and that the presence of $\mathrm{SiC}$ nanoparticles and smaller nanoparticles in nanocomposites had more beneficial influence on erosive wear resistance.
\end{abstract}

Keywords: ZA-27 alloy; nanocomposites; nanoparticles; compocasting; fractography; erosive wear

\section{Introduction}

Erosive wear can be defined as "loss of material from a solid surface due to relative motion in contact with solid particles which are entrained in a fluid or due to the action of streaming liquid, gas or gas containing liquid droplets" [1]. The first part of this definition corresponds to solid particles' erosion, and the second part, to fluid erosion. Solid particles' erosion is more often observed in practice and has two special cases: abrasive erosion (erosion in which the relative motion of the solid particles is nearly parallel to the solid surface) and impingement or impact erosion (erosion in which the relative motion of the solid particles is nearly normal to the solid surface). Fluid erosion does not normally include cavitation erosion (cavitation wear), nor electrical erosion (electrical pitting) [2].

* Corresponding author: Aleksandar VENCL, E-mail: avencl@mas.bg.ac.rs 
In general, the erosive wear properties of a material depend on various operating parameters such as angle of particle/fluid impact; kinetic energy of the particle/fluid on impact; size, shape, amount, and type of particles carried by the fluid; and properties of the eroded material. Erosive wear properties of a material also depend very much on eroded material properties, such as microstructure and mechanical properties. Materials can be divided into two groups according to their response to erosive wear. For ductile materials, the highest erosive wear is when the impact angle is between $20^{\circ}$ and $30^{\circ}$, while for brittle materials, the highest erosive wear is when the impact angle is approximately $90^{\circ}$ [2]. In addition, experiments on metals, ceramics, and polymers have clearly indicated that the hardness of the eroding material by itself cannot adequately explain the observed behavior [3]. As a result, combined parameters involving both hardness and fracture toughness have been utilized to correlate the erosion data [4-5].

Metal matrix nanocomposites (MMnCs) represent a relatively new class of material, and consist of a metal matrix filled with nanosized reinforcements (nanoparticles or carbon nanotubes) with physical and mechanical properties very different from those of the matrix. They can be produced by various processing techniques [6]. The nanosized reinforcements can improve the matrix material in terms of fracture strength and toughness, hardness, and wear resistance [6]. Due to the reinforcement's size, properties of MMnCs are dominated by their surface characteristics, rather than their bulk properties, which is the case with microsized reinforcements. In addition, the reduced size of the reinforcement phase down to the nanoscale is such that interaction of particles with dislocations becomes of significant importance and, when added to other strengthening effects, typically found in conventional metal matrix composites (MMCs), results in improved mechanical properties.

The ZA-27 alloy [7] is a zinc-aluminum casting alloy that has been frequently used in sliding bearings and bushings intended for high-load/low-speed applications and other wear resistant applications [8-10]. In ZA-27 alloy-based nanocomposites, the metal matrix should provide ductility and toughness, while ceramic reinforcements will give high strength and hardness. According to the results of our previous study [11], the presence of nanosized reinforcements led to the formation of a finer structure in the nanocomposites matrix, and improvement in the basic mechanical properties (hardness and compressive yield strength). In view of above, the present paper is in a certain way a follow up to our research activities, i.e., the goal of this study was to investigate whether the improvement in mechanical properties is accompanied with equivalent or even superior erosive wear properties of manufactured MMnCs.

Several MMnCs based on ZA-27 alloy are investigated, i.e., $\mathrm{MMnCs}$ reinforced with 0.2 wt. $\%, 0.3 \mathrm{wt} . \%$, and 0.5 wt. $\% \mathrm{SiC}$ (particle size $<50 \mathrm{~nm}$ ), $\mathrm{Al}_{2} \mathrm{O}_{3}$ (particle size 20-30 nm) and $\mathrm{Al}_{2} \mathrm{O}_{3}$ (particle size approx. $100 \mathrm{~nm}$ ). These MMnCs are produced through the compocasting process with mechanical alloying pre-processing, and their erosive wear resistance is determined through the solid particles erosion testing. Influences of type, amount, and size of nanoparticles on the erosive wear properties of tested MMnCs were also analyzed.

\section{Experimental details}

\subsection{Materials}

The matrix material used as the basis for obtaining composites was the zinc-aluminum alloy ZA-27, with the chemical composition shown in Table 1. This material obtained by semi-solid processing (thixocasting) was used as a reference material (designated as ZA-27 thixo). The apparatus used for the semi-solid processing of the matrix alloy and MMnCs (nanocomposites) is described elsewhere [12]. The parameters of the thixocasting and compocasting process, for the purpose of comparison, were similar in production of ZA-27 thixo and the nanocomposites samples. A detailed description of the experimental procedure is presented elsewhere [11].

Table 1 Chemical composition (wt. \%) of ZA-27 alloy.

\begin{tabular}{ccccc}
\hline Element & $\mathrm{Al}$ & $\mathrm{Cu}$ & $\mathrm{Mg}$ & $\mathrm{Zn}$ \\
\hline Percentage & $25-27$ & $2.0-2.5$ & $0.015-0.02$ & Balance \\
\hline
\end{tabular}


Nine different nanocomposites based on the ZA-27 alloy were investigated, i.e., nanocomposites reinforced with $0.2,0.3$, and $0.5 \mathrm{wt}$.\% $\mathrm{SiC}$ (particle size $<50 \mathrm{~nm}$ ), $\mathrm{Al}_{2} \mathrm{O}_{3}$ (particle size 20-30 nm), and $\mathrm{Al}_{2} \mathrm{O}_{3}$ (particle size approx. $100 \mathrm{~nm}$ ). The designation of the tested nanocomposites and used type, amount, and size of nanoparticles (reinforcement) are shown in Table 2. These nanocomposites were produced through the compocasting process with mechanical alloying preprocessing (ball milling). During ball milling, which was performed before the compocasting process, metal chips of the matrix alloy were mechanically alloyed with nanoparticle reinforcements. The ball milling was carried out in air, at room temperature, at a rotational speed of $500 \mathrm{rpm}$, using alumina balls with diameters of $10 \mathrm{~mm}$ and $14 \mathrm{~mm}$ (with a 60:40 percentage ratio), for $60 \mathrm{~min}$. The metal chips-tonanoparticles weight ratio was $3: 1$, while the alumina ball-to-milling mixture weight ratio was 5:1. After semi-solid processing, all samples (ZA-27 thixo and nanocomposites samples) were subjected to hotpressing at $370{ }^{\circ} \mathrm{C}$ at a pressure of $250 \mathrm{MPa}$.

The microstructures and mechanical properties (hardness and compressive yield strength) of the tested materials were investigated and analyzed in our previous study [11]. In short, the microstructures of the ZA-27 thixo material and all nanocomposites are similar and non-dendritic, but the size of the $\alpha$ phase particles in the ZA-27 thixo material is larger, indicating a more homogeneous structure of nanocomposite matrices. In addition, the size of the $\eta$

Table 2 Designation of the tested nanocomposites and used reinforcements.

\begin{tabular}{cccc}
\hline \multirow{2}{*}{$\begin{array}{c}\text { Nanocomposite } \\
\text { designation }\end{array}$} & Type & $\begin{array}{c}\text { Amount } \\
(\text { wt. } \%)\end{array}$ & $\begin{array}{c}\text { Approximate } \\
\text { size (nm) }\end{array}$ \\
\cline { 3 - 4 } N1: $0.2-50$ & & 0.2 & \\
N2: $0.3-50$ & SiC & 0.3 & 50 \\
N3: $0.5-50$ & & 0.5 & \\
\hline N4: $0.2-25$ & & 0.2 & 25 \\
N5: $0.3-25$ & & 0.3 & \\
N6: $0.5-25$ & & 0.5 & 100 \\
N7: $0.2-100$ & $\mathrm{Al}_{2} \mathrm{O}_{3}$ & 0.2 & \\
N8: $0.3-100$ & & 0.3 & \\
N9: $0.5-100$ & & 0.5 & \\
\hline
\end{tabular}

phase regions (rich in zinc) was narrowed in all nanocomposites compared with the ZA-27 thixo material. Certain porosity and agglomeration of nanoparticles (clustering) were noticed in nanocomposites, and the highest were in nanocomposites with $0.5 \mathrm{wt} . \%$ nanosized reinforcements, regardless the reinforcement type/size.

The results of hardness measurements and compression tests indicate the beneficial effect of nanoparticle reinforcements, i.e., tested nanocomposites had higher hardness and compressive yield strength than the ZA-27 thixo material, regardless of the reinforcement type/amount/size. It was noticed that the increase in the amount of nanoparticles from 0.2 to $0.3 \mathrm{wt} . \%$ increased the hardness and compressive yield strength of the nanocomposites. Further increase in the amount of nanoparticles to $0.5 \mathrm{wt} . \%$ led to a decrease in hardness (probably due to higher porosity of these samples) and to further increase in compressive yield strength. The influence of porosity on the values of compressive yield strength was reduced during the compression tests, probably owing to the condensation of pores considering the force direction in the compression tests. Nanocomposites with $\mathrm{SiC}$ nanoparticles showed higher values of hardness and compressive yield strength than nanocomposites with $\mathrm{Al}_{2} \mathrm{O}_{3}$ nanoparticles. In the case of nanocomposites with $\mathrm{Al}_{2} \mathrm{O}_{3}$ nanoparticles, hardness and compressive yield strength were higher for nanocomposites with smaller nanoparticles $(25 \mathrm{~nm})$ than for nanocomposites with larger nanoparticles $(100 \mathrm{~nm})$.

\subsection{Erosive wear tests}

Erosive wear tests were carried out on jet nozzle type erosion equipment (Fig. 1) in ambient air at room temperature. This testing utilizes repeated gasentrained solid particle impingement erosion, and involves a small nozzle delivering a stream of gas containing solid particles that impacts the surface of a test specimen. Solid particles are poured from the reservoir (1), freefalling onto the nozzle tube (2). The length of the nozzle is $200 \mathrm{~mm}$, diameter is $8 \mathrm{~mm}$, and exit diameter is $6 \mathrm{~mm}$. Before the tests, solid particles material was sieved through a set of sieves and dried in an oven to remove moisture from the particles. As the particles were crushed, they had sharp edges and 
had irregular morphology. The air stream is provided by the compressed air at controlled pressure, purified from particles and moisture (3). The air stream also enters the nozzle tube (2), where the formation of a two-phase (particle-air) working stream takes place. The test sample (4), with a rectangular shape $(30 \mathrm{~mm} \times$ $20 \mathrm{~mm}$ ) and $6 \mathrm{~mm}$ thickness, is fixed in a holder (5) attached to the reversing mechanism (6). With the reversing mechanism (6), two working parameters are controlled: (a) the distance of the sample from the nozzle and (b) the impact angle of the particles.

The parameters used in the erosive wear tests (solid particles material, maximum size of the particles, air stream pressure, particles flow, particles impact angle, distance between the sample and the nozzle, and duration of the test) were the same for all tested materials (Table 3). A particles impact angle of $90^{\circ}$ was chosen in order to achieve minimal erosive wear, as the tested materials are more ductile than brittle,

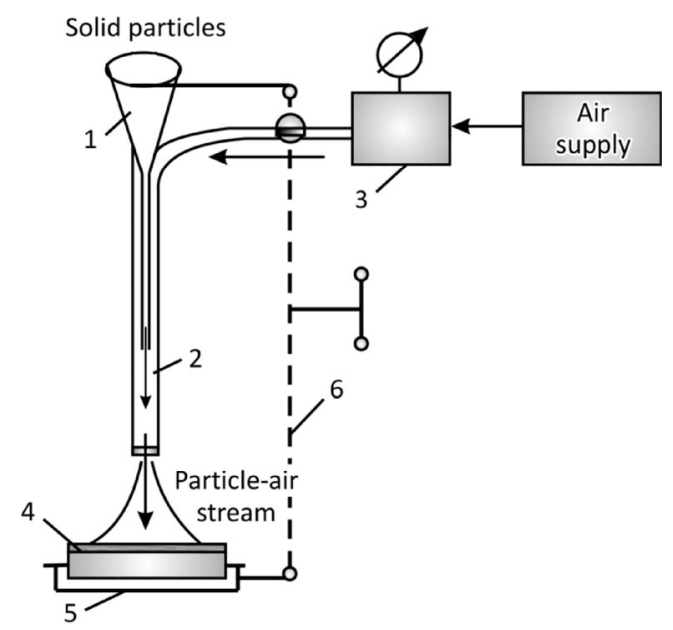

Fig. 1 Schematic of erosive wear testing.

Table 3 Parameters used in the erosive wear tests.

\begin{tabular}{cc}
\hline Test parameter & Value \\
\hline Solid particles material & $\begin{array}{c}\text { Black corundum } \\
\left(\mathrm{Al}_{2} \mathrm{O}_{3}\right)\end{array}$ \\
Maximum size of the particles & $630 \mu \mathrm{m}$ \\
Air stream pressure & $0.2 \mathrm{MPa}$ \\
Particles flow & $167 \mathrm{~g} / \mathrm{min}$ \\
Particles impact angle & $90^{\circ}$ \\
Distance between the sample and & $10 \mathrm{~mm}$ \\
the nozzle & 3 minutes \\
Duration of the test &
\end{tabular}

and not foreseen for the applications in which solid particles will have small impact angles. By testing ductile materials, it is easier to choose other parameters like the size of the solid particles, as it is well known that the erosion wear rate is substantially more sensitive to particle size for brittle than for ductile materials [3].

Erosive wear is calculated as a mass loss, i.e., as a difference between the initial mass of the sample and its mass after the end of test. Before and after testing, the samples were degreased and cleaned, and their mass was measured by an electronic balance with an accuracy of $0.1 \mathrm{mg}$. In order to achieve a higher confidence level when evaluating the test results, two replicate tests were conducted for each material. After the testing, the worn surfaces of the test samples were examined with a scanning electron microscope (SEM).

\section{Results and discussion}

\subsection{Fractography}

Samples for the fractographic examinations $(15 \mathrm{~mm}$ $\times 8 \mathrm{~mm} \times 8 \mathrm{~mm}$ ) were notched in the middle of the longest side before the tests, fixed, and fractured manually by hammer. Fractographic examinations were performed by means of SEM, and fracture surfaces of the nanocomposites with $0.3 \mathrm{wt} . \%$ nanoparticles (N2: 0.3-50, N5: 0.3-25 and N8: 0.3-100) are shown in Fig. 2. The fracture morphology of the nanocomposites N2: 0.3-50 and N5: 0.3-25 (Figs. 2(a) and 2(b)) is similar to the fracture morphology of the ZA-27 thixo material, which was described earlier [13]. The presence of a ductile fracture in the regions of $\alpha$ phase and in the region of the $\alpha+\eta$ phase mixture is characteristic for the ZA-27 thixo material, as well as transition from ductile to brittle intergranular fracture, in the $\eta$ phase (rich in zinc) regions [13].

The regions of ductile fracture with characteristic serpentine glides were found to be broadened in nanocomposites N2: 0.3-50 and N5: 0.3-25, compared with the size of these regions in the ZA-27 thixo material [13], indicating the increase in ductility of these nanocomposites. The presence of $\mathrm{Al}_{2} \mathrm{O}_{3}$ nanoparticles ( $25 \mathrm{~nm}$ particle size) or $\mathrm{SiC}$ nanoparticles $(50 \mathrm{~nm}$ particle size) led to a broadening of the $\alpha+\eta$ phase mixture regions and a narrowing of the $\eta$ phase 


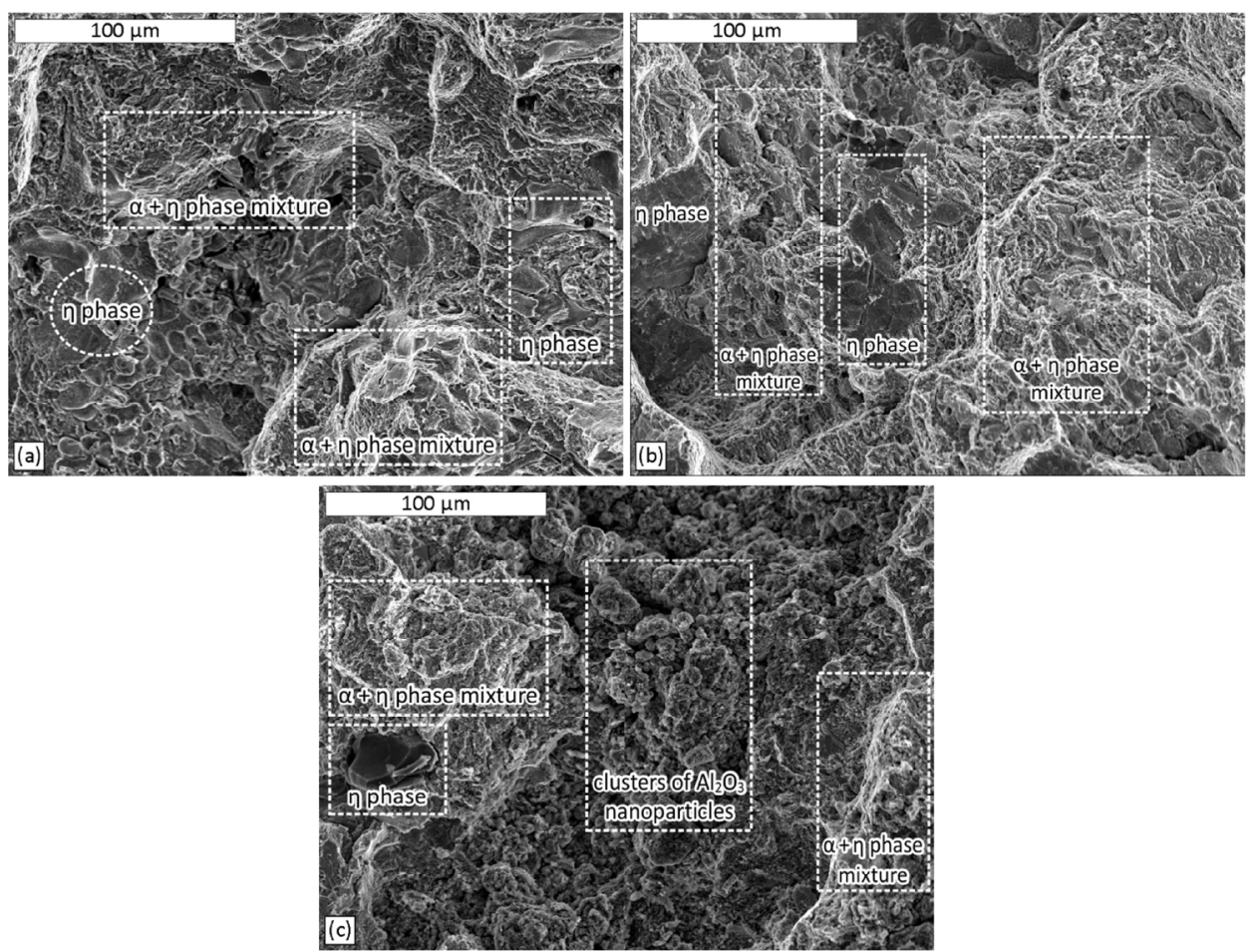

Fig. 2 Fracture surface of nanocomposites with 0.3 wt.\% nanoparticles: (a) nanocomposite N2: 0.3-50, (b) nanocomposite N5: 0.3-25, and (c) nanocomposite N8: 0.3-100.

regions in the nanocomposite matrices. In the case of the nanocomposite with larger $\mathrm{Al}_{2} \mathrm{O}_{3}$ nanoparticles (100 nm particle size), i.e., nanocomposite N8: 0.3-100 (Fig. 2(c)), the regions of ductile and brittle fracture are also clearly visible. In addition, the brittle decohesive fracture between the clusters (agglomerations) of $\mathrm{Al}_{2} \mathrm{O}_{3}$ nanoparticles and the matrix is noticed in this nanocomposite.

\subsection{Erosive wear properties}

The results of the erosive wear tests are shown in Table 4. For some materials, the difference in measured mass loss between two replicate tests is relatively high. This occurs due to the differences in structure homogeneity of tested materials and the imperfection of the production process, which is done in laboratory conditions. Nevertheless, for the discussion of general trends of behavior, these results should be satisfactory. It is for this reason that the average values of mass loss are used for the wear rate calculations (Table 4). Wear rate is calculated as the mass loss of the sample material divided by the mass of the applied solid particles material during the test $(500 \mathrm{~g})$.
The first thing that could be noticed is that nanocomposites generally showed higher erosive wear resistance (lower wear rate) than the matrix alloy (ZA-27 thixo material). This is the opposite behavior in relation to the behavior of the MMCs reinforced with a higher amount of larger microsized ceramic particles, which usually have a lowered capacity to absorb strain, resulting in a greater plastic constraint upon impact and facilitating material removal by microfracture. At a particles impact angle of $90^{\circ}$, the energy of impact results in plastic deformation together with the fracture of reinforcements and liberation of fragmented reinforcements [14].

Generally higher erosive wear resistance of nanocomposites in comparison to the matrix alloy (the ZA-27 thixo material), could be partially explained with their higher hardness and higher compressive yield strength. However, this is not always the case, as hardness, for example, is a good indicator of erosive wear resistance only for annealed pure metals when using small particles impact angles (abrasion erosion). This positive effect diminishes, however, with increasing impact angles. As a result, a softer material can show 
Table 4 Mass loss and calculated average wear rate of tested materials.

\begin{tabular}{|c|c|c|c|}
\hline $\begin{array}{c}\text { Material } \\
\text { designation }\end{array}$ & Sample & $\begin{array}{c}\text { Mass } \\
\text { loss (mg) }\end{array}$ & $\begin{array}{c}\text { Average wear } \\
\text { rate } \times 10^{-2}(\mathrm{mg} / \mathrm{g})\end{array}$ \\
\hline \multirow{2}{*}{ ZA-27 thixo } & 1 & 7.2 & \multirow{2}{*}{1.37} \\
\hline & 2 & 6.5 & \\
\hline \multirow{2}{*}{ N1: $0.2-50$} & 1 & 6.3 & \multirow{2}{*}{1.23} \\
\hline & 2 & 6.0 & \\
\hline \multirow{2}{*}{$\mathrm{N} 2: 0.3-50$} & 1 & 6.6 & \multirow{2}{*}{1.11} \\
\hline & 2 & 4.5 & \\
\hline \multirow{2}{*}{ N3: $0.5-50$} & 1 & 5.6 & \multirow{2}{*}{1.11} \\
\hline & 2 & 5.5 & \\
\hline \multirow{2}{*}{ N4: $0.2-25$} & 1 & 5.8 & \multirow{2}{*}{1.25} \\
\hline & 2 & 6.7 & \\
\hline \multirow{2}{*}{ N5: $0.3-25$} & 1 & 6.2 & \multirow{2}{*}{1.12} \\
\hline & 2 & 5.0 & \\
\hline \multirow{2}{*}{ N6: $0.5-25$} & 1 & 8.0 & \multirow{2}{*}{1.38} \\
\hline & 2 & 5.8 & \\
\hline \multirow{2}{*}{ N7: $0.2-100$} & 1 & 7.5 & \multirow{2}{*}{1.60} \\
\hline & 2 & 8.5 & \\
\hline \multirow{2}{*}{ N8: $0.3-100$} & 1 & 5.0 & \multirow{2}{*}{1.00} \\
\hline & 2 & 5.0 & \\
\hline \multirow{2}{*}{ N9: $0.5-100$} & 1 & 7.5 & \multirow{2}{*}{1.35} \\
\hline & 2 & 6.0 & \\
\hline
\end{tabular}

higher erosion resistance than a harder one. Changing a material's hardness will, in general, affect other mechanical properties, for example ductility [3, 15].

An additional explanation of the higher erosive wear resistance of nanocomposites, in comparison to the matrix alloy (ZA-27 thixo material), is that the presence of nanoparticles led to the formation of a finer structure and reduction in the regions of brittle fracture ( $\eta$ phase regions) in the nanocomposite matrices. The presence of nanoparticles also led to the strengthening of the nanocomposites, and the largest contribution to the overall strengthening was due to the enhanced dislocation density strengthening mechanism [11]. The possible presence of this and several other strengthening mechanisms in MMnCs, with their influences, is discussed by Casati and Vedani [16]. The fact that the improvements in specific material properties can be achieved by adding only a small percentage of nanosized particles was confirmed by Rohatgi and Schultz [6].
It can also be noticed in Table 4 is that the best erosive wear resistance was exhibited by nanocomposites with $0.3 \mathrm{wt}$.\% nanoparticles, regardless of the type or size of nanoparticles. This is more obvious in Fig. 3, where the average values of wear rate for three different nanocomposites with the same wt.\%. are presented, i.e., wear rate averages of N1: 0.2-50, N4: 0.2-25, and N7: 0.2-100 nanocomposites, N2: 0.3-50, N5: 0.3-25, and N8: 0.3-100 nanocomposites, and N3: 0.5-50, N6: 0.5-25, and N9: 0.5-100 nanocomposites.

It was already shown that the presence of nanoparticles led to the strengthening of the nanocomposites, and that the strengthening effect was higher with higher amounts (wt.\%) of nanoparticles [11]. With this in mind, the erosive wear rate of nanocomposites with $0.5 \mathrm{wt}$ \% nanoparticles should be the lowest, i.e., lower than the wear rate of nanocomposites with $0.3 \mathrm{wt}$.\% nanoparticles. This is not the case due to the presence of higher porosity and agglomeration of nanoparticles (clustering) in nanocomposites with $0.5 \mathrm{wt} . \%$ nanoparticles. These clusters were responsible for brittle decohesive fractures, which were confirmed with fractography analysis (Fig. 2(c)), and which are not favorable in erosive wear testing with particles impact angle of $90^{\circ}$. The presence of higher porosity and agglomeration of nanoparticles (clustering) also influenced the hardness values of nanocomposites with 0.5 wt.\% nanoparticles, which also were lower than the hardness values of nanocomposites with $0.3 \mathrm{wt} . \%$ nanoparticles. All this suggests that, concerning erosive wear resistance, there is an optimal amount of nanoparticles in MMnCs,

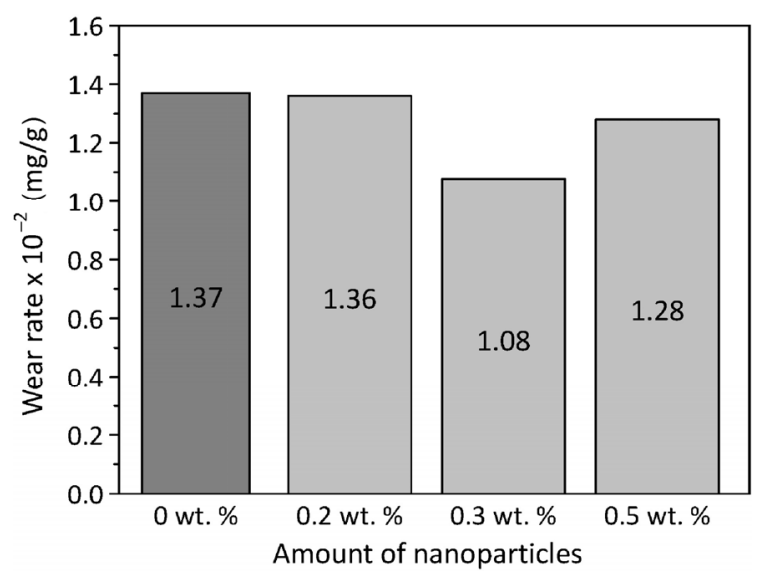

Fig. 3 Influence of the amount of nanoparticles on the erosive wear rate of tested materials. 
depending on the testing conditions and production process, which does not have to be the highest amount and which in our case was $0.3 \mathrm{wt} . \%$.

The influences of type and size of nanoparticles on the erosive wear resistance of tested nanocomposites were analyzed by comparing the average wear rates of nanocomposites with the same type and size of nanoparticles (Fig. 4), i.e., wear rate averages of the N1: 0.2-50, N2: 0.3-50, and N3: 0.5-50 nanocomposites, N4: 0.225, N5: 0.3-25, and N6: 0.5-25 nanocomposites, and N7: 0.2-100, N8: 0.3-100, and N9: 0.5-100 nanocomposites. By averaging the wear rates of the nanocomposites with different amount of nanoparticles, the effects of porosity and agglomeration of nanoparticles, which were noticed in nanocomposites with $0.5 \mathrm{wt}$.\% nanoparticles, are diminished or eliminated.

The presence of $\mathrm{SiC}$ nanoparticles in nanocomposites had a more beneficial influence on their erosive wear resistance than the presence of $\mathrm{Al}_{2} \mathrm{O}_{3}$ nanoparticles, regardless of the size of $\mathrm{Al}_{2} \mathrm{O}_{3}$ nanoparticles (Fig. 4). Nanocomposites with $\mathrm{SiC}$ nanoparticles had higher hardness and higher compressive yield strengths than nanocomposites with $\mathrm{Al}_{2} \mathrm{O}_{3}$ nanoparticles. In addition, regions of ductile fracture were slightly broader in nanocomposites with $\mathrm{SiC}$ nanoparticles (Fig. 2(a)), which had a beneficial effect on the erosive wear rate when tests were performed with particles impact angle of $90^{\circ}$. Analyzing the size of nanoparticles (Fig. 4), it can be concluded that smaller nanoparticles had a more beneficial influence on erosive wear resistance. Nanocomposites with smaller $\mathrm{Al}_{2} \mathrm{O}_{3}$ nanoparticles ( $25 \mathrm{~nm}$ particle size) had higher hardness

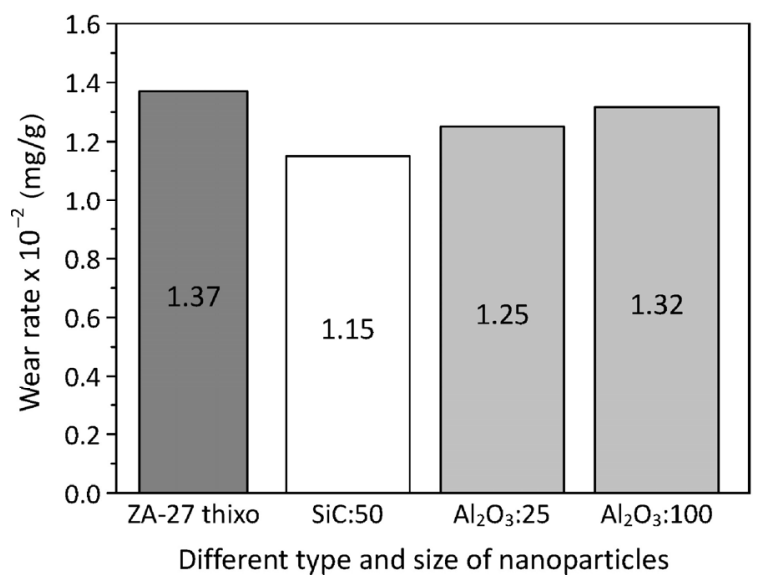

Fig. 4 Influences of the type and size of nanoparticles on the erosive wear rate of tested materials. and higher compressive yield strengths than nanocomposites with larger $\mathrm{Al}_{2} \mathrm{O}_{3}$ nanoparticles (100 nm particle size). In addition, it was probably easier for smaller nanoparticles to enhance the density of dislocation, i.e., strengthening of the nanocomposites was more pronounced in nanocomposites with smaller nanoparticles. Further, nanocomposites with larger $\mathrm{Al}_{2} \mathrm{O}_{3}$ nanoparticles (100 nm particle size) showed brittle decohesive fractures between the clusters (agglomerations) of $\mathrm{Al}_{2} \mathrm{O}_{3}$ nanoparticles (Fig. 2(c)), which is not favorable in erosive wear testing with particles impact angle of $90^{\circ}$.

The calculated average wear rates of tested materials shown in Fig. 4 are in correlation with their hardness and compressive yield strength values (Fig. 5). Higher hardness values correspond to lower erosive wear rates, and lower compressive yield strengths correspond to higher erosive wear rates. The rates of correlations are expressed through the $R^{2}$ (R-squared) values, which show acceptable goodness of fit $\left(R^{2}=1\right.$ is a perfect fit), i.e., $R^{2}=0.99$ for erosive wear rate vs. hardness, and $R^{2}=0.95$ for erosive wear rate vs. compressive yield strength.

Worn surface analysis of tested nanocomposites was performed after erosive wear testing. The test samples flat surfaces with dimensions of $30 \mathrm{~mm} \times$ $20 \mathrm{~mm}$ were exposed to erosive wear, and the resulting worn surface areas had circular shapes (Fig. 6). In addition, worn surfaces were examined by means of SEM (Fig. 7). It is well known that multi-particle impingement involves complex phenomena, such as particle interaction and particles embedded in the surface [17]. Several erosive wear processes can occur

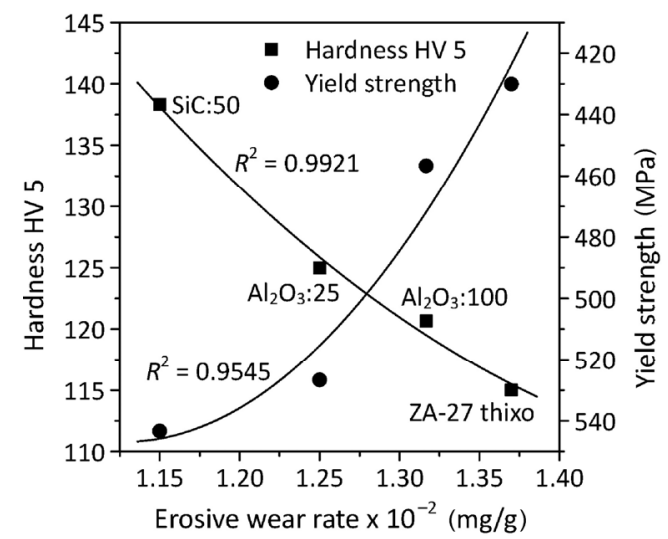

Fig. 5 Erosive wear rate vs. hardness and compressive yield strength of tested materials. 


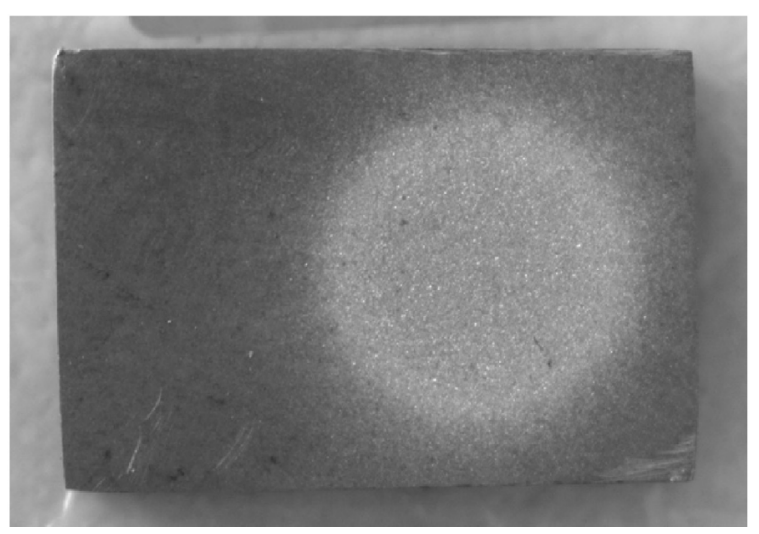

Fig. 6 Test sample and worn surface area.

in practice, e.g., formation of material lips around the craters smeared by subsequent impacts of particles; formation of surface or subsurface cracks promoted by the repeated loading cycles by multiple impact of particles; formation of thin platelets, etc. [3]. Additionally, these processes can occur simultaneously, depending on the operating conditions and the target material.

All nanocomposites showed similar worn surface appearance (Fig. 7), which is typical for erosive wear [18]. The presence of grooves and chips caused by the plowing action of erosive particles, material lips of plastically deformed and extruded material, and subsurface cracks promoted by surface fatigue can be noticed. Nevertheless, the presence of surface cracks was not noticed. In general, the worn surface showed a high degree of plastic deformation, which could have resulted in different substructures, such as dislocation tangles or dislocation cells, or thermally induced processes such as recovery or recrystallization [3].

\section{Conclusions}

An analysis of the fractography examinations (which was performed in parallel to the erosive wear testing) reveals that the presence of nanoparticles did not decrease the ductility of tested nanocomposites. On the contrary, the regions of ductile fracture (regions of $\alpha$ phase and $\alpha+\eta$ phase mixture) were broader in nanocomposites when compared with those in the matrix alloy (ZA-27 thixo material). This led to the increased erosive wear resistance of the nanocomposites, as the erosive wear testing was performed with a particles impact angle of $90^{\circ}$.

The higher erosive wear resistance of tested nanocomposites when compared with the matrix alloy (ZA-27 thixo material) was also due to their finer microstructure, better mechanical properties (hardness and compressive yield strength), and overall strengthening of the nanocomposite matrices induced by the presence of nanoparticles.

The performed analysis of the influences of type, amount, and size of nanoparticles on the erosive wear resistance of tested nanocomposites showed that there was an optimal amount of nanoparticles, which in our case was $0.3 \mathrm{wt} . \%$. Further, the presence of $\mathrm{SiC}$ nanoparticles and smaller nanoparticles in the nanocomposites had a more beneficial influence on the erosive wear resistance for the test conditions used.

The worn surface analysis showed evidence of a high degree of plastic deformation on the worn surfaces of the nanocomposites. Their appearance was typical for erosive wear, with the presence of grooves caused by plowing action of erosive particles, material lips
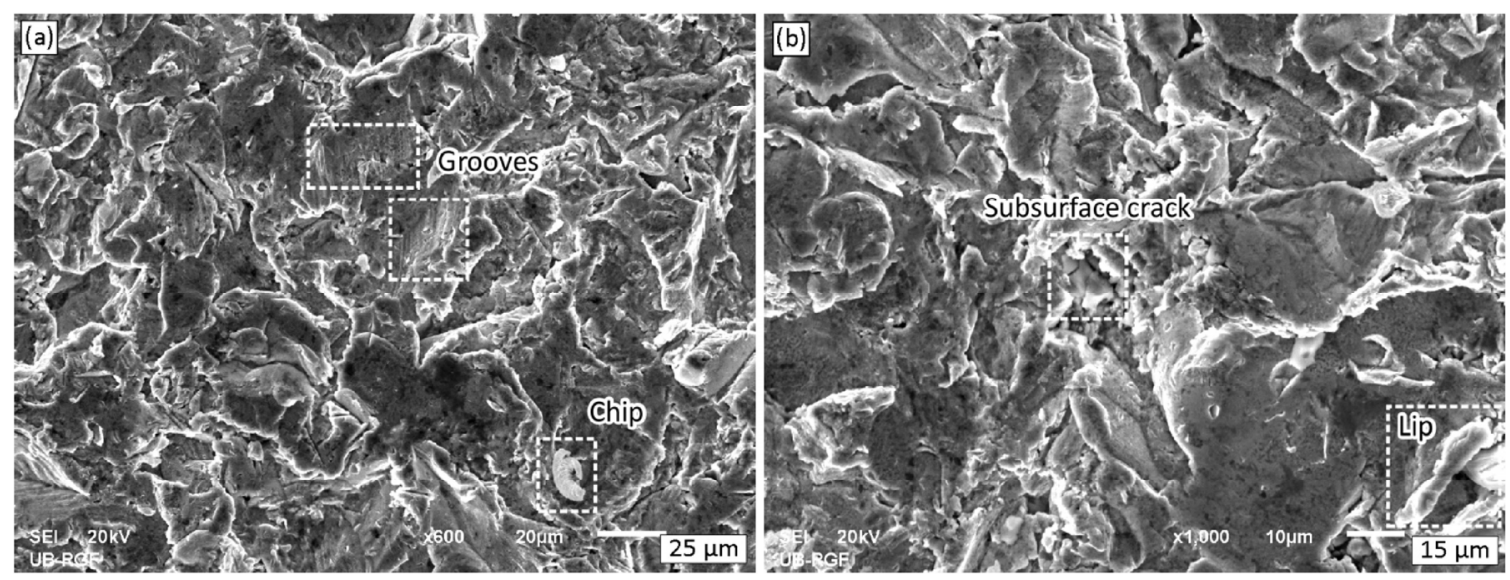

Fig. 7 Worn surface top-view of nanocomposite N3: 0.5-50, reinforced with SiC nanoparticles, at different magnifications of SEM. 
of plastically deformed and extruded material, and subsurface cracks promoted by the surface fatigue. Nevertheless, the presence of surface cracks was not observed.

\section{Acknowledgements}

This work has been performed as a part of activities within the projects TR 34028, TR 35021, and OI 172005. These projects are supported by the Republic of Serbia, Ministry of Education, Science and Technological Development, whose financial help is gratefully acknowledged. Petr Svoboda acknowledges the project LO1202, funded by the MEYS under the National Sustainability Programme I. Mara Kandeva acknowledges the project $\not \mathrm{H}$ 07/28-15.12.2016, funded by the National Science Fund of the Ministry of Education and Science, Bulgaria. Collaboration through the CEEPUS network CIII-BG-0703 and the COST action CA15102 is also acknowledged.

Open Access: The articles published in this journal are distributed under the terms of the Creative Commons Attribution 4.0 International License (http:// creativecommons.org/licenses/by/4.0/), which permits unrestricted use, distribution, and reproduction in any medium, provided you give appropriate credit to the original author(s) and the source, provide a link to the Creative Commons license, and indicate if changes were made.

\section{References}

[1] OECD, Research Group on Wear of Engineering Materials. Glossary of Terms and Definitions in the Field of Friction, Wear and Lubrication: Tribology. Paris: OECD, 1969.

[2] Kandeva M, Vencl A, Karastoyanov D. Advanced Tribological Coatings for Heavy-Duty Applications: Case Studies. Sofia: Prof. Marin Drinov Publishing House of Bulgarian Academy of Science, 2016.

[3] Zum Gahr K H. Microstructure and Wear of Materials. Amsterdam: Elsevier, 1987.

[4] Ericson F, Johansson S, Schweitz J A.. Hardness and fracture toughness of semiconducting materials studied by indentation and erosion techniques. Mater Sci Eng A 105-106: 131-141 (1988)

[5] Lamy B. Effect of brittleness index and sliding speed on the morphology of surface scratching in abrasive or erosive processes. Tribol Int 17(1): 35-38 (1984)

[6] Rohatgi P K, Schultz B. Lightweight metal matrix nanocomposites-Stretching the boundaries of metals. Mater Matt 2(4): 16-20 (2007)

[7] ASTM International. ASTM B86-13 Standard specification for zinc and zinc-aluminum (ZA) alloy foundry and die castings. 2013.

[8] Prasad B K, Yegneswaran A H, Patwardhan A K. Characterization of the wear response of a modified zincbased alloy vis-à-vis a conventional zinc-based alloy and a bearing bronze at a high sliding speed. Metall Materials Trans A 27(11): 3513-3523 (1996)

[9] Gervais E, Barnhurst R J, Loong C A. An analysis of selected properties of ZA alloys. JOM 37(11): 43-47 (1985)

[10] Lyon R. High strength zinc alloys for engineering applications in the motor car. Met Mater 1(1): 55-57 (1985)

[11] Bobić B, Vencl A, Ružić J, Bobić I, Damnjanović Z. Microstructural and basic mechanical characteristics of ZA27 alloy-based nanocomposites, synthesized by mechanical milling and compocasting. J Compos Mater: submitted for publication.

[12] Vencl A, Bobić I, Jovanović M T, Babić M, Mitrović S. Microstructural and tribological properties of A356 Al-Si alloy reinforced with $\mathrm{Al}_{2} \mathrm{O}_{3}$ particles. Tribol Lett 32(3): 159-170 (2008)

[13] Bobić I, Babić M, Vencl A, Bobić B, Mitrović S. Artificial aging of thixocast ZA27 alloy and particulate $\mathrm{ZA} 27 / \mathrm{SiC}_{\mathrm{p}}$ composites. Int J Mater Res 104(10): 954-965 (2013)

[14] Wilson S, Ball A. Wear resistance of an aluminium matrix composite. In The Engineering Development and Application of Composite Materials. Johannesburg, South Africa, 1990.

[15] Cousens A K. The erosion of ductile metals by solid particle impact. Ph.D Thesis. Cambridge: University of Cambridge, 1984.

[16] Casati R, Vedani M. Metal matrix composites reinforced by nano-particles-A review. Metals, 4(1): 65-83 (2014)

[17] Finnie I. Erosion of surfaces by solid particles. Wear 3(2): 87-103 (1960)

[18] Laguna-Camacho J R, Vite-Torres M, Gallardo-Hernández E A, Vera-Cárdenas E E. Solid particle erosion on different metallic materials. In Tribology in Engineering. Pihtili H, Ed. Rijeka: InTech, 2013: 63-78. 


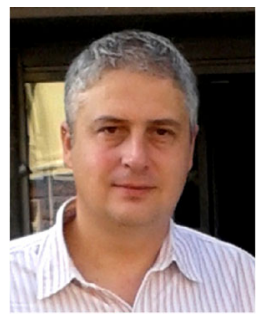

Aleksandar VENCL. He received his MSc degree in engineering materials in 2002 and $\mathrm{PhD}$ degree in tribology in 2008 from the Faculty of Mechanical Engineering at University of Belgrade, Serbia. His current position is a full professor and head of Tribology Laboratory at University of

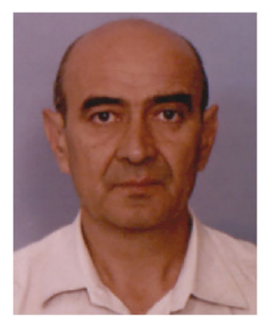

Ilija BOBIĆ. He received his $\mathrm{BSc}$ MSc and $\mathrm{PhD}$ degrees in metallurgical engineering from the Faculty of Technology and Metallurgy at University of Belgrade, Serbia. He joined the Laboratory for Materials at Institute of Nuclear

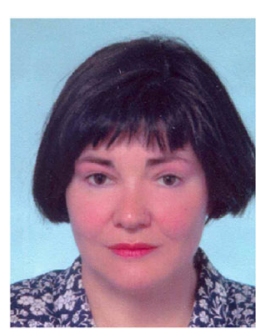

Biljana BOBIĆ. She received her BSc degree in electrochemistry and her $\mathrm{PhD}$ degree in metallurgical engineering from the Faculty of Technology and Metallurgy at University of Belgrade, Serbia. She was employed at the Military Technical Institute - Belgrade. In 2013, she joined the

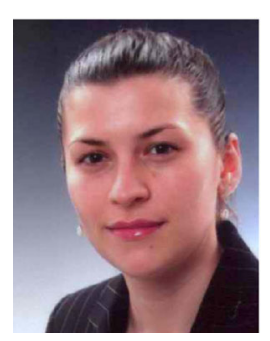

Kristina JAKIMOVSKA. She is an assistant professor at Ss. Cyril and Methodius University, Faculty of Mechanical Engineering in Skopje, Macedonia. In 2005 she started working as teaching and research assistant at Institute of Mechanical Construction, Mechanization Machines and Vehicles at the Faculty of Mechanical Engineering in Skopje.
Belgrade, Faculty of Mechanical Engineering. His main research fields are friction and wear characteristics of materials (metals, polymers, ceramics and composites), surface modifications and coatings, lubricants (application, recycling and monitoring), nanotribology and failure diagnostic of tribological systems.

Sciences "Vinca", University of Belgrade from 1986. His current position is principal research fellow in the Laboratory for Materials. His main research interests include synthesis and characterization of metal-matrix composites with micro- and nanoceramic reinforcements and graphite, as well as casting of special metallic materials.

Department of Electrochemistry at Institute of Chemistry, Technology and Metallurgy, University of Belgrade. Her current position is senior research associate in the Department of Electrochemistry. Her principal research activities include corrosion engineering and surface characterization using electrochemical and microscopic techniques.

She received her PhD degree from the same faculty in 2014 and in 2015 she finished her post-doc studies in the framework of FP7 project - AComIn at the Institute of Information and Communication Technologies at the Bulgarian Academy of Sciences in Sofia. Her research interests include tribology, transport and logistics, mechanization machines, and materials. 


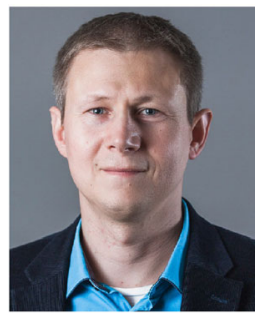

Petr SVOBODA. He received his MSc and PhD degrees in mechanical engineering from Brno University of Technology, Czech Republic, in 2005 and 2009, respectively. His current position is an associate professor and member of elastohy-

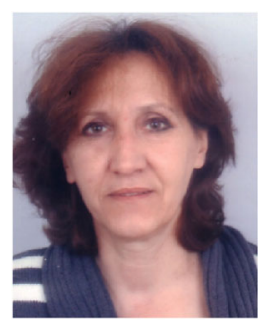

Mara KANDEVA. She is a professor at the Faculty of Industrial Technologies (FIT) and head of the Center "Tribology" at the Technical University of Sofia, Bulgaria. She is author and co-author of more than drodynamic lubrication section at tribology group, Institute of Machine and Industrial Design, Faculty of Mechanical Engineering, Brno University of Technology. His research areas cover the boundary, mixed and elastohydrodynamic lubrication, starvation, surface texturing effect and lubricant rheology.

200 scientific publications, monographs and textbooks on tribology and machine dynamics. She was chairman of the Balkan Tribological Association (2008-2010) and is currently president of the Society of Bulgarian Tribologists (2008 - up to now). 